disturbed, while a child with a severe ventilatory defect may have minimal emotional disturbance.

The design of this study was such that only limited answers could be given to some of the questions asked. The methodology aimed to reduce complex aspects of personality behaviour and family relations to simple reproducible parameters that could be objectively scored on digital coding scales. The advantages and limitations are obvious. When significant differences were found the observations were almost certainly valid but the cut-off points may have been too rigid, so that a complete range of behavioural disturbances and relationships were not revealed. Whether behavioural disturbances were specific to asthma, whether they were consequent on asthma or preceded its development, or whether they were the result of disturbed family relations are important questions which remain unanswered. They will be answered only by specifically designed prospective studies in which asthmatic and control samples of both normal children and children with chronic illness will be randomly selected and the clinical, physiological, and allergic aspects of the asthmatic samples clearly defined.

This study was supported by a grant from the Asthma Foundation of Victoria.

\section{References}

Alcock, T. (1960). British fournal of Medical Psychology, 33, 133. Creak, M., and Stephens, J. M. (1958). Pediatric Clinics of North America, 5,731 .

Dawson, B., Horabin, G., Illsley, R., and Mitchell, R. (1969). Lancet, 1, 827. Dubo, S., et al. (1961). Fournal of Pediatrics, 59, 402.

Feingold, B. F., Singer, M. T., Freeman, E. H., and Deskins, A. (1966). fournal of Allergy, 38, 143.

Freeman, E. H., Feingold, B. F., Schlesinger, K., and Gorman, F. J. (1964). Psychosomatic Medicine, 26, 543.

French, T. M., and Alexander, F. (1941). Psychosomatic Medicine; Monograph Series $(I V)$. National Research Council, Washington D.C.

Graham, P. J., Rutter, M. L., Yule, W., and Pless, I. B. (1967). British Fournal of Preventive and Social Medicine, 21, 78.

Gunnarson, S. (1950). International Archives of Allergy and Applied Im-

munology, 1, 103.
McNicol, K. N., and Williams, H. E. (1973 a). British Medical fournal, $4,7$.

McNicol, K. N., and Williams, H. E. (1973 b). British Medical fournal, 4,12 .

Mansmann, J. A. (1952). Annals of Allergy, 10, 583.

Miller, H., and Baruch, D. W. (1948). Psychosomatic Medicine, 10, 275.

Neuhaus, E. C. (1958). Psychosomatic Medicine, 20, 181.

Pinkerton, P. (1967). Journal of Psychosomatic Research, 11, 11.

Rees, L. (1956). Fournal of Psychosomatic Research, 1, 212.

Rogerson, C. H., Hardcastle, D. H., and Duguid, K. (1935). Guy's Hospital Reports, 85, 289 .

Strauss, E. B. (1935). Guy's Hospital Reports, 85, 309.

Williams, H. E., and McNicol, K. N. (1969). British Medical fournal, 4, 321.

Williams, J. S. (1973). Fournal of Child Psychology and Psychiatry and Allied Disciplines. In press.

\title{
Area Differences in Spontaneous Abortion Rates in South Wales and Their Relation to Neural Tube Defect Incidence
}

\author{
C. J. ROBERTS, SETSUKO LLOYD
}

British Medical fournal, 1973, 4, 20-22

\section{Summary}

Data are presented from the South Wales Congenital Malformation Survey (92,982 births 1964-6 inclusive) showing that within areas in South Wales there exists an inverse relation between previous spontaneous abortion rate and the prevalence at birth of neural tube defect (anencephaly or spina bifida cystica or both). This relation is independent of social class, parity, and maternal age, and is not likely to be explained by area differences in accuracy of reporting previous spontaneous abortions.

On the basis of these findings a hypothesis is advanced which proposes that the incidence of neural tube defects is uniform throughout South Wales and that the present substantial and relatively stable differences in area prevalence are controlled by small area differences in mortality of malformed embryos. This would seem to suggest that factors initiating the malformation are genetic and that any related environmental factors exert their effect on already abnormal fetuses by influencing, in one way or another, their capacity to survive.

\section{Introduction}

Support for the view that environment is an important factor in

\footnotetext{
Department of Social and Occupational Medicine, Welsh National School of Medicine, Cardiff CF4 4XN C. J. ROBERTS, PH.D., M.D., Senior Lecturer SETSUKO LLOYD, B.SC., Scientific Officer
}

the aetiology of neural tube defect (anencephaly or spina bifida cystica or both) derives from the epidemiological finding of an association between neural tube defect incidence on the one hand and variables such as parity, social class, season, and place of birth on the other. "Incidence" in this context is used loosely when what is in fact described is "prevalence" at the time of birth. The critical issue when making inferences on aetiology is the extent to which prevalence at birth is an accurate reflection of incidence in early pregnancy, or as Lowe (1972) picturesquely put it, the extent to which "what comes down at birth is a guide to what went up at conception."

Observed differences of prevalence at birth, then, can be the result of differences in incidence in early pregnancy, differences in malformed embryonic mortality, or both. When two populations are compared it follows that the use of birth prevalence of neutral tube defects as an index of incidence in early pregnancy can be justified only if it is assumed that malformed embryonic mortality rates are the same for each population.

We present evidence from the South Wales Congenital Malformation Study which suggests that malformed embryonic mortality rates are not constant from one area population to another, and we discuss the implications this has for making inferences on differences in neural tube defect incidence.

\section{Sources of Data}

For three years beginning 1 January 1964 information was collected about all infants born to women resident in South Wales and about all the congenital defects identified in that birth population (Richards and Lowe, 1971). The survey area comprised two counties (Glamorgan and Monmouthshire) and the four county boroughs within their boundaries (Cardiff, Swansea, Merthyr Tydfil, and Newport). In the three years of the investigation 92,982 infants (live and stillbirth) were born to women resident in the area. Of these infants 90,921 were the 
outcome of singleton pregnancies and 2,061 of multiple pregnancies. In this paper we confine our attention to the singleton infants and to the neural tube defects among them, and the reported frequencies of spontaneous abortion among the preceding pregnancies.

\section{Results}

The rates of neural tube malformation in the different areas of South Wales have been reported in detail elsewhere (Richards et al., 1972). Briefly, the prevalence at birth in 48 individual local authority areas varied by a factor of 5 (from 3 to 15 per 1,000 births) but in order to overcome the problem of small numbers of births in some areas the 48 areas were grouped together into eight larger regions. The resulting group area prevalence of total neural tube malformations was found to vary (see table I) by a factor of 2, being highest in the east and west mining valleys of Glamorgan (10.0 and 9.4 per 1,000 singleton births respectively) and the Monmouthshire mining valleys (8.9) and lowest in the rest of Monmouthshire (6.5) and Newport $(5 \cdot 2)$. For the purpose of this study we therefore divided South Wales into two areas with approximately similar numbers of births, but with contrasting prevalence rates for neural tube defects. Area A comprised the 28 inland local authorities of the Glamorganshire and Monmouthshire mining valleys (singleton birth population 42,327) and area $B$ comprised the 20 largely coastal local authorities of Glamorganshire, Monmouthshire, Cardiff, Swansea, and Newport (singleton birth population 48,594).

TABLE I-Neural Tube Malformation Rates in South Wales (1964-6) by Year and Region of Birth

\begin{tabular}{|c|c|c|c|c|c|}
\hline \multirow{2}{*}{ Region } & \multirow{2}{*}{$\begin{array}{l}\text { No. of } \\
\text { Singleton } \\
\text { Births }\end{array}$} & \multicolumn{3}{|c|}{ Rates per 1,000 Births } & \multirow{2}{*}{$\begin{array}{c}\text { Mean } \\
\text { Rate } \\
1964-6\end{array}$} \\
\hline & & 1964 & 1965 & 1966 & \\
\hline $\begin{array}{l}\text { Glamorgan } \\
\text { E. valleys } \\
\text { Glamorgan W. valleys } \\
\text { Monmouthshire valleys } \\
\text { Swansea } \quad . . \\
\text { Cardiff. } \quad . . \\
\text { Rest Glamorgan } \\
\text { Rest Monmouthshire } \\
\text { Newport }\end{array}$ & $\begin{array}{r}17,738 \\
11,278 \\
13,309 \\
8,419 \\
14,453 \\
13,823 \\
5,361 \\
6,540\end{array}$ & $\begin{array}{l}7.96 \\
8.95 \\
7.92 \\
8.04 \\
6.93 \\
6.21 \\
6.25 \\
5.65\end{array}$ & $\begin{aligned} 10 \cdot 96 \\
8 \cdot 65 \\
9 \cdot 11 \\
6 \cdot 65 \\
8 \cdot 55 \\
6 \cdot 76 \\
4 \cdot 18 \\
6 \cdot 64\end{aligned}$ & $\begin{aligned} 11 \cdot 25 \\
10 \cdot 69 \\
9 \cdot 60 \\
9 \cdot 62 \\
7 \cdot 16 \\
7 \cdot 67 \\
9 \cdot 47 \\
3 \cdot 25\end{aligned}$ & $\begin{aligned} 10 \cdot 03 \\
9 \cdot 40 \\
8 \cdot 87 \\
8 \cdot 08 \\
7 \cdot 54 \\
6 \cdot 87 \\
6 \cdot 53 \\
5 \cdot 20\end{aligned}$ \\
\hline
\end{tabular}

Rank correlation coefficients: $1964-5$, r $0.55 ; 1965-6$, r 0.60; 1964-6, r 0.86 .

The frequency of reported previous spontaneous abortions among mothers living in area $A$ are compared in table II with that of mothers living in area B. Six categories of mothers are considered-namely, mothers whose infants have neural tube defects (by parity 0,1 , and $2+$ ) and mothers of all notified singletons without neural tube defects (by parity 0,1 , and $2+$ ). In each of the six categories the reported previous spontaneous abortion rates were lower in mothers living in the mining

TABLE II-Previous Spontaneous Abortion by Area of Birth in South Wales. Numbers in Parenthesis are Actual Numbers of Women Reporting Previous Abortions

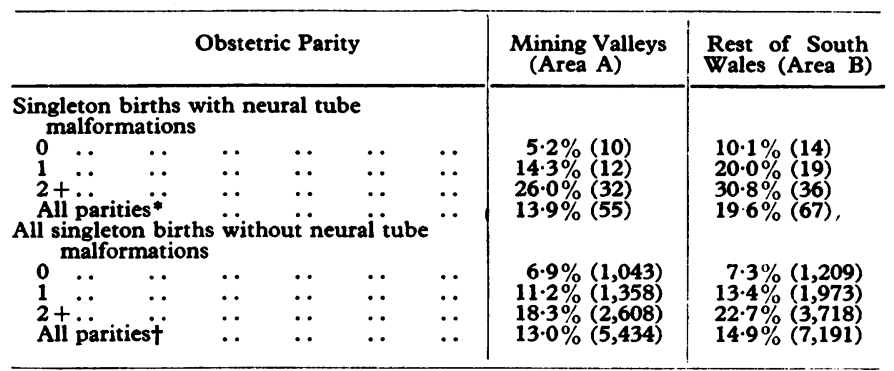

P $<0.05$.

"All parities" include the cases with unknown parity. valleys than in mothers living in the rest of South Wales. The difference in proportion of reported history of abortion between the two areas is statistically significant, both for neural tube defects $(P<0.05)$ and for infants without neural tube defects $(P<0.001)$.

It is possible that maternal age differences between one area and another could give rise to area differences in spontaneous abortion. However, in South Wales from 1964-6 there were no significant area differences in maternal age distribution (Richards et al., 1972) and we therefore reject this as an explanation of our findings.

In order to test the possibility that the findings in table II may reflect reporting differences arising from social class differences between areas the data were analysed by area, social class, and parity (table III). These findings confirm that the higher reported spontaneous abortion rates in area B cannot be explained on the basis of reporting differences arising from differences in socioeconomic status. The consistency of the direction of the difference in all categories in table III greatly strengthens the likelihood that the previous spontaneous abortion rate is indeed higher in area B than in area $A$.

TABLE III-Previous Spontaneous Abortion by Area of Birth and Social Class. Numbers in Parenthesis are Actual Numbers of Women Reporting Previous Abortion

\begin{tabular}{|c|c|c|}
\hline & $\underset{\text { (Area A) }}{\text { Mining Valleys }}$ & $\underset{\text { (Area B) }}{\text { Rest }}$ \\
\hline $\begin{array}{c}0 \\
1 \\
2 \\
3 \\
4 \\
5 \cdot 6 \\
7.8 .9+\end{array}$ & $\begin{array}{c}\text { Manual Class: } \\
7 \cdot 2 \%(794) \\
10.9 \%(1,010) \\
15 \cdot 2 \%(836) \\
18.4 \%(519) \\
21 \cdot 7 \%(301) \\
23.6 \%(272) \\
31 \cdot 3 \%(141)\end{array}$ & $\begin{array}{l}7 \cdot 3 \%(709) \\
13 \cdot 1 \%(1,228) \\
18 \cdot 1 \%(1,003) \\
22 \cdot 4 \%(651) \\
28.1 \%(431) \\
32 \cdot 3 \%(394) \\
34.9 \%(151)\end{array}$ \\
\hline Total & $12 \cdot 2 \%(3,873)$ & $14 \cdot 8 \%(4,567)$ \\
\hline $\begin{array}{l}0 \\
1 \\
2 \\
3 \\
4+\end{array}$ & $\begin{array}{r}\text { Non-manual Class: } \\
6 \cdot 7 \%(208) \\
12 \cdot 7 \%(303) \\
15 \cdot 3 \%(189) \\
18.5 \%(88) \\
24.2 \%(39)\end{array}$ & $\begin{array}{r}8 \cdot 0 \%(456) \\
14.3 \%(672) \\
16 \cdot 6 \%(407) \\
22 \cdot 2 \%(225) \\
27 \cdot 7 \%(108)\end{array}$ \\
\hline Total & $11 \cdot 6 \%(876)$ & $13 \cdot 4 \%(1,943)$ \\
\hline
\end{tabular}

\section{Discussion}

In the ensuing discussion, for the purpose of simplicity, we have considered only. the spontaneous abortion of embryos with central nervous system abnormalities. However, it can be shown that a consideration of all spontaneous abortions will in no way alter implications for the interrelationship between incidence, prevalence, and embryonic mortality of neural tube defects.

Let $100=$ number of all conceptions

and $i=$ the number of those with neural tube defects

then $100-i=$ the number of conceptions without neural tube defects

Let $m=$ proportion of neural tube defects aborted

then $\mathrm{mi}=$ number of neural tube defects aborted

then $p$, which is the prevalence at birth of neural tube defects will be $\mathbf{i}-\mathbf{m i}$

$$
\overline{100-\mathrm{mi}}
$$

Using the above formula the relation between $m$ and $i$ for specified values of $p$ can be plotted (see graph). Taking $p=1 \%$ (the approximate observed value for area $A$ ) and $p=0.5 \%$ (the approximate observed value for area $B$ ) any curves with $p$ values lying between $0.5 \%$ and $1 \%$ will lie between the curves shown in the graph. From the graph it seems likely that area differences in the proportion of neural tube defects aborted (m) are subtle and not very large. In table IV we have estimated i from a series 


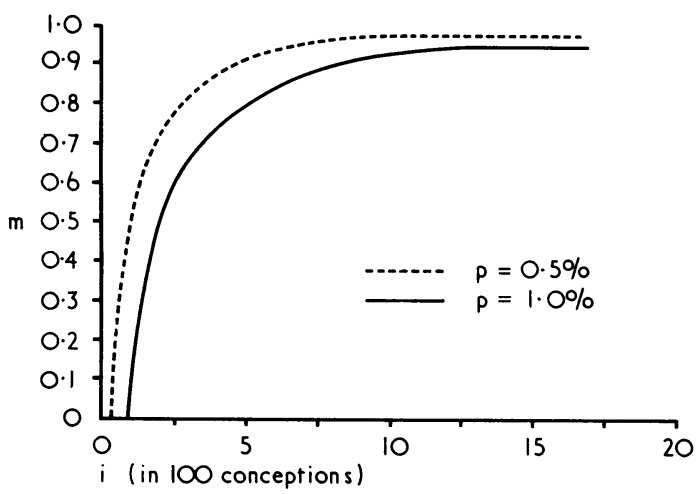

Relation between proportion of neural tube defects aborted (m) and number of neural tube defects in 100 conceptions (i) when prevalence at birth (p) $=0.5 \%$ and $1 \%$.

of $\mathrm{m}$ values for area $\mathrm{B}$ assuming $(a)$ that the proportion of neural tube defects aborted $(\mathrm{m})$ in area $\mathrm{A}$ is $95 \% \mathrm{~m}$ in area $\mathrm{B}$, and (b) that these $m$ values range around a central value of 0.92 (derived from published data by Nishimura, 1969). Table IV shows firstly, that the estimated $i$ value for area $A$ is only slightly greater than that for area B and therefore alone could not possibly explain the observed doubling of prevalence at birth between area $A$ and area $B$, and secondly, that as the proportion of neural tube defects aborted $(m)$ in area $B$ increases towards a critical value of 0.95 the incidence values for areas A and B come very close together (yet still maintain a two-fold difference in prevalence). This example suggests that much more careful thought should be given to the estimation of the number of aborted embryos and fetuses so that relations (environmental and genetic) can

TABLE IV-Estimates of Area Incidence (i) From a Series of Embryonic Mortality Values (m) Based on Nishimura's (1969) Data, and Taking $P($ Area $A)=1 \%$ and $P($ Area $B)=0.5 \%$ based on the South Wales Data

\begin{tabular}{c|c|c|c}
\hline \multicolumn{2}{c|}{$\begin{array}{c}\text { Proportion of Neural Tube Defects } \\
\text { Aborted (m) }\end{array}$} & \multicolumn{2}{c}{$\begin{array}{c}\text { No. of Neural Tube Defects in } 100 \\
\text { Conceptions (i) }\end{array}$} \\
\hline Area B & Area A & Area B & Area A \\
\hline 0.88 & 0.836 & 4.0 & 5.8 \\
0.90 & 0.855 & 4.8 & 6.5 \\
0.92 & 0.874 & 5.9 & 7.4 \\
0.94 & 0.893 & 7.7 & 8.6 \\
0.96 & 0.912 & 11.2 & 10.3 \\
\hline
\end{tabular}

be sought in terms of incidence early in pregnancy and not prevalence at birth for various areas.

It is tempting at this stage to propose the hypothesis that the incidence early in pregnancy of neural tube defect is uniform throughout the areas of South Wales and that the present substantial and relatively stable differences in area prevalence at birth are controlled by small area differences in mortality of malformed embryos. This would seem to suggest that the factors initiating the malformation are genetic and that any related environmental factors exert their effect on abnormal fetuses by influencing, one way or another, their capacity to survive. One merit of this hypothesis is its economy. By assuming uniform area incidence there is left only the problem of explaining area differences in spontaneous abortion rate. Alternative hypotheses would need to assume area differences in both incidence and spontaneous abortion rates and would therefore require complex explanations based on at least two independent but interacting mechanisms-one to explain abortion differences and the other to explain incidence differences. It seems not only more logical to accept the simpler explanation but also that what evidence is available-that is, of malformation rates among abortions-points strongly towards the embryonic mortality of malformed conceptuses as a factor of over-riding importance in the determination of malformation prevalence at birth.

We acknowledge with gratitude the generous grant from the Association for the Aid of Crippled Children, New York, which made this investigation possible. It is with pleasure that we also acknowledge our indebtedness to the Medical Officers of Health of Cardiff, Merthyr Tydfil, Newport, Swansea, Glamorgan, and Monmouthshire for their interest and co-operation, and to the many consultant obstetricians, paediatricians, pathologists, dermatologists, and orthopaedic, plastic, and ophthalmic surgeons who have notified and continue to notify us of the names of infants in our birth population who have come to their attention with congenital defects. We are also grateful to Dr. J. Howlett and Mrs. J. Lay, of the Atlas Computer Laboratory, Chilton, Berks, for the help they and their staff have always given us.

\section{References}

Lowe, C. R. (1972). British Medical fournal, 2, 515.

Nishimura, $\mathrm{H}$ (1969). In Congenital Malformations. Proceedings of the Third International Conference, ed. F. C. Fraser, V. A McK usick, and R International Conference, ed. F. C. Fraser, V. A. McKusick, and R. Robinson, p. 275. Amsterdam, Excerpta Medica Foundation.

Richards, I. D. G., and Lowe, C. R. (1971). British fournal of Preventive and Social Medicine, 25, 59

Richards, I. D. G., Roberts, C. J., and Lloyd, S. (1972). British fournal of Preventive and Social Medicine, 26, 89. 